\title{
A comparison between aerosols modelled and measured by AERONET network emitted by vegetation fires over Iberian Peninsula
}

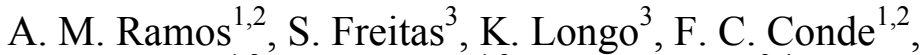 \\ J. Corte-Real ${ }^{1,2}$, A. M. Silva ${ }^{1,2}$, A. L Fazenda ${ }^{3,4}$, F. S. Recuero ${ }^{3}$ \\ \& D. S. Moreira ${ }^{3}$ \\ ${ }^{1}$ Department of Physics, University of Évora. Évora, Portugal \\ ${ }^{2}$ Geophysics Centre of Évora (CGE), University of Évora, \\ Évora, Portugal \\ ${ }^{3}$ Center for Weather Prediction and Climate Studies, CPTEC/INPE, \\ Cachoeira Paulista, São Paulo, Brazil \\ ${ }^{4}$ Department of Informatics, Taubaté, São Paulo, Brazil
}

\section{Abstract}

This work aims at validating the CATT-BRAMS model which can simulate emissions and transport of aerosol and trace gases from forest fires which occurred in the Iberian Peninsula on the period from 7 to 12 August 2003. The validation of the generated aerosol concentrations values was made by comparison with AERONET (Aerosol Robotic Network) aerosol optical thickness (AOT) measurements at two different wavelengths, which is a quantity that is related to the aerosol load in the atmospheric column.

Keywords: aerosol optical thickness, Angström exponent, transport model, biomass burning.

\section{Introduction}

Forest fires in Europe are a major source of concern for environmental security. Every year several hundred thousand hectares are burned throughout European forests. These fires put at risk, not only human life and property but also the sustainability of forests and other woodlands. The regeneration of vegetation after fire, mainly in the Mediterranean area, can be slow and consequently 
favours the erosion and soil loss processes. Hence, it is important to do a yearly assessment of the total surface burned and of the type of land cover affected to estimate the damage.

Summer 2003 was one of the most severe fire seasons experienced during the last decades in Southern Europe. Record temperatures across Europe, reaching over $40 \mathrm{C}$ in some countries, caused some of the worst forest fires ever seen stoked forest fires from Poland to the Iberian Peninsula. According to the European Forest Fires Information System (Schmuck et al. [1]) the total area of forest burnt was 647,069 hectares - four times the size of Greater London. More than half (390,146 hectares) were in Portugal, making it the worst forest fire season the country had faced in the last 23 years. Spain registered during the same period extreme temperatures of $46^{\circ} \mathrm{C}$ in the south and $51^{\circ} \mathrm{C}$ in the city of Sevilla. Forest fires burning 70 kilometers east of Madrid and in Salamanca destroyed about 2.000 hectares of forest.

This work aims at validating the CATT-BRAMS model which can generated aerosol concentrations values produced by forest fires occurred in the Iberian Peninsula during the period 7-12 August 2003. The validation of the generated aerosol concentrations values was made by comparison with AERONET (Aerosol Robotic Network) aerosol optical thickness (AOT) measurements at two different wavelengths $(440 \mathrm{~nm}$ and $870 \mathrm{~nm})$, which is a quantity that is related to the aerosol load in the atmospheric column.

\section{Data and methods}

\subsection{AERONET data}

NASA's AERONET (AErosol RObotic NETwork) program consists of a group of ground-based remote sensing instruments in the United States that can determine the amount of aerosols, or tiny particles of pollutants, that are in the air over a given location. The goal of this ground network is to assess the optical properties of aerosols, specifically how much sunlight they scatter and absorb, and to provide a double-check of aerosol data as gathered by satellites. The network imposes standardization of instruments, calibration, and processing. Data from this collaboration provides globally distributed observations of spectral aerosol optical depths, inversion products, and precipitable water in geographically diverse aerosol regimes. Episodes of forest fires aerosols are identified by increases in aerosol optical thickness particularly in $440 \mathrm{~nm}$ and $870 \mathrm{~nm}$ wavelengths and decreases in the Angström turbidity parameter (Angström exponent) - indicating larger aerosols. Descriptions may be found of program objectives, affiliations, the instrumentation, operational issues, data products, database browser "demonstrat", research activities, links to similar data sets, NASA EOS links and personnel involved in AERONET.

For the area under study, the available data is located at two sites, one at Évora city $\left(38.5678^{\circ} \mathrm{N} ; 7.9115^{\circ} \mathrm{W}\right)$, Portugal and the other one at El Arenosillo city $\left(37.105^{\circ} \mathrm{N} ; 6.73347^{\circ} \mathrm{W}\right)$, Spain. The site Évora is located in the southwestern part of the Iberian Peninsula, in a rural area, remote from sources of 
industrial pollution, $100 \mathrm{~km}$ away from the Atlantic coast. The station El Arenosillo is located in Huelva province in the south-west Atlantic coast of Spain (see figure 1). El Arenosillo is surrounded by a pine tree forest and is located within Donana National Park, a protected coastal area.

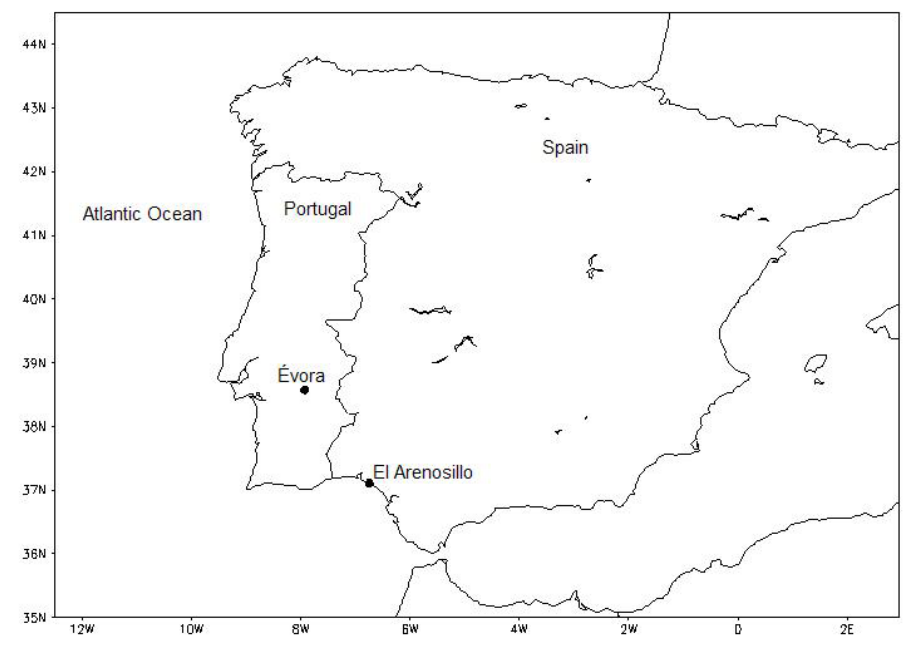

Figure 1: The location of the AERONET network over Iberian Peninsula: Évora city, in Portugal and El Aeronosillo city, in Spain.

\subsection{Description CATT-BRAMS Model}

The on-line 3-D transport model follows the Eulerian approach being coupled to the Brazilian developments on the Regional Atmospheric Modeling System (BRAMS) 3.2 version (http://www.cptec.inpe.br/brams). The RAMS is a multipurpose, numerical prediction model designed to simulate atmospheric circulations spanning in scale from hemispheric scales down to large eddy simulations (LES) of the planetary boundary layer. The equation set used is the quasi-Boussinesq nonhydrostatic equations described by Tripoli and Cotton [2]. The model is equipped with a multiple grid nesting scheme which allows the model equations to be solved simultaneously on any number of interacting computational meshes of differing spatial resolution. It has a complex set of packages to simulate processes such as: radiative transfer, surface-air water, heat and momentum exchanges, turbulent planetary boundary layer transport and cloud microphysics. The initial conditions can be defined from various observational data sets that can be combined and processed with a mesoscale isentropic data analysis package (Tremback et al. [3]). For the boundary conditions, the 4DDA schemes allow the atmospheric fields to be nudged towards the large-scale data. New deep and shallow convective schemes based on the mass flux approach and with several types of closure (Grell and Devenyi [4]) were also implemented. 
The biomass burning source emission parameterization (for $\mathrm{CO}, \mathrm{CO} 2, \mathrm{CH} 4$, $\mathrm{NO}_{\mathrm{x}}$ and $\mathrm{PM}_{2.5}$ ) is based on the MODIS fire observation and field observations. For each fire detected by remote sensing, the mass of emitted tracer is calculated and its emission in the model follows a diurnal cycle of the burning (Freitas et al. [5]). The type of vegetation that is burning is obtained from the IGBP $1 \mathrm{~km}$ vegetation map, thus allowing an appropriate selection of the vegetation dependent factors in mass emission estimation.

The sources are spatially and temporally distributed and daily assimilated according to the biomass burning spots defined by the satellite observations. The carbon monoxide emission associated to the anthropogenic processes (industrial, power generation, transportation, etc) is provided by EDGAR database (http://arch.rivm.nl/env/int/coredata/edgar/). All biomass burning emissions are added with the EDGAR "agricultural waste burn" and "fuelwood burning" emissions with $1 \mathrm{x} 1$ degree horizontal resolution and 1 year time resolution. For $\mathrm{PM}_{2.5}$, the tracer convective transport scheme accounts also for the wet (in and below cloud) deposition based on the work of Berge [6].

\subsubsection{Model configuration, initial and boundary conditions}

The initial and lateral boundary conditions necessary to drive CATT-BRAMS were provided by the twice daily Aviation run of the National Centers for Environmental Prediction Global Spectral Model (AVN) with a resolution $1.25 \times 1.25$ degrees. The model is set up with two tri-dimensional grids. The coarse grid specification was defined with $80 \mathrm{~km}$ grid spacing and the other two with $20 \mathrm{~km}$, both centered at $38.8^{\circ} \mathrm{N} ; 9.28^{\circ} \mathrm{W}$ (Lisbon). The vertical resolution starts at $150 \mathrm{~m}$ near the surface, stretching at a rate of 1.10 to a final resolution of $850 \mathrm{~m}$, with the model top at about $21 \mathrm{~km}$. The time step was $60 \mathrm{~s}$ for grid 1 and $30 \mathrm{~s}$ for grid 2.

The BRAMS full microphysics package was activated for all the grids. This scheme includes the use of generalised gamma distributions as the basic function for all hydrometeor species; the use of a heat budget equation for hydrometeor classes, allowing heat storage and mixed phase hydrometeors (Walko et al. [7]). Grell cumulus parameterization scheme improved by Grell and Devenyi [4], radiation parameterization from Chen and Cotton [8], turbulence and diffusion parameterizations were handled using the Mellor and Yamada [9] was activated in two grids. Topography, vegetation type, land percentage and sea surface temperature were read onto the grid from USGS (U.S. Geological Survey at $1 \mathrm{~km}$ horizontal resolution) datasets. The simulation utilized silhouette-averaged topography (Bossert [10]) in order to incorporate the desired terrain effects. A soil model was assumed, using seven levels with 50\% saturation moisture for all depths (Tremback and Kessler [11]) and constant inflow conditions are used to the tracer boundary condition and the emission sources of biomass burning aerosols were obtained from the MODIS/TERRA fire product combined with local observations made available for Europe. 


\section{Results}

During the first half of August 2003 a severe heat wave hit Western and Central Europe. The persistent anticyclonic conditions characterized by exceptionally high temperatures low values of relative humidity with average flow presented a predominant direction northwest over Iberian Peninsula were favourable to the development of a large-scale pollution episode. The stagnation of the air mass also led to the accumulation of the primary emitted particulate matter (PM) and the development of secondary aerosols (Vautard et al [12]). Furthermore, in conjunction with the dry, hot weather conditions, the Southern part of Europe was influenced by significant forest fires that generated a huge amount of primary particles, principally in Portugal (EFFIS).

Figures 2 and 3 show the times series of aerosol optical thickness from AERONET in the $440 \mathrm{~nm}$ and $870 \mathrm{~nm}$ wavelengths, Angström exponent and modelled column concentration of $\mathrm{PM}_{2.5}\left(\mu \mathrm{g} \cdot \mathrm{m}^{-2}\right)$ simulated by CATT-BRAMS in Évora city, Portugal and El Arenosillo city, Spain, respectively, on the period from 7 to 12 August 2003. The results show a good agreement between modelled aerosol concentrations and the aerosol optical thickness at $440 \mathrm{~nm}$ and $870 \mathrm{~nm}$ measured at Évora, although the agreement is better at the smaller wavelength. This can be explained since at smaller wavelengths the aerosol optical thickness is larger and more sensitive to smaller particles, which is normally the case of burning-originated aerosols.

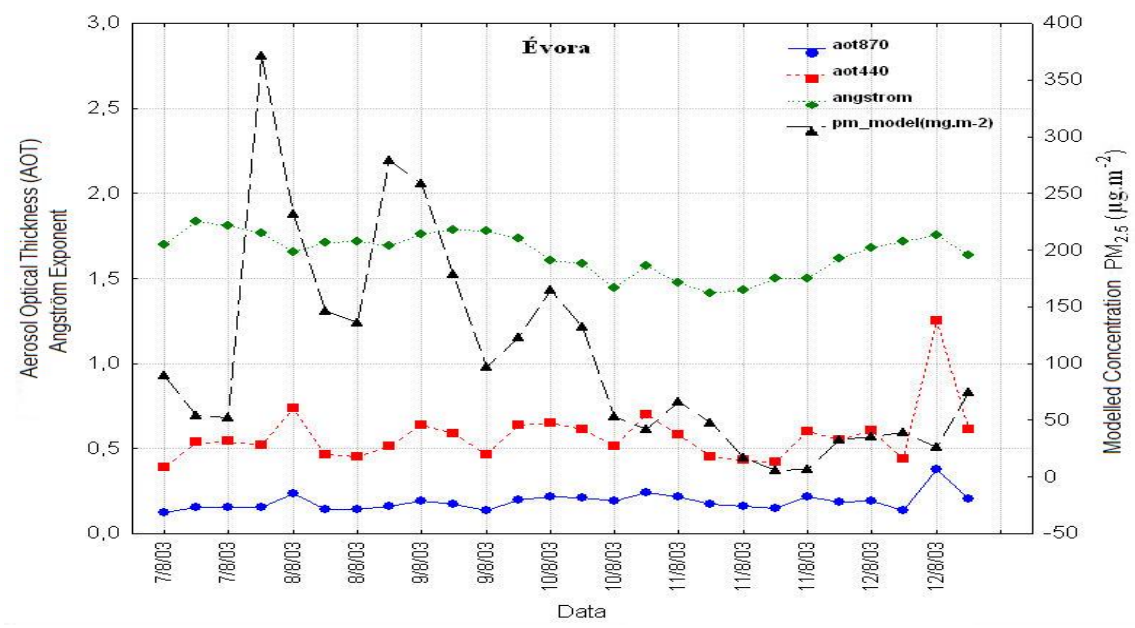

Figure 2: Time series of aerosol optical thickness from AERONET in the $440 \mathrm{~nm}$ and $870 \mathrm{~nm}$ wavelengths, Angström exponent and modelled column concentration of $\mathrm{PM}_{2.5}\left(\mu \mathrm{g} \cdot \mathrm{m}^{-2}\right)$ simulated by CATT-BRAMS in Évora city $\left(38.5678^{\circ} \mathrm{N} ; 7.9115^{\circ} \mathrm{W}\right)$, Portugal on the period from 7 to 12 August 2003. 
For El Arenosillo the situation is quite different since a mixture of different aerosol types are present: together with biomass burning aerosols, generated at the south of France and Spain an intrusion of desert dust aerosols appears on the 8 August followed by a decrease on the 11 August. The modelled aerosol concentration is relatively low; due to the fact the fire sources were located far away from El Arenosillo with distinct meteorological conditions, whereas at Évora site the fire sources were located close to the site.

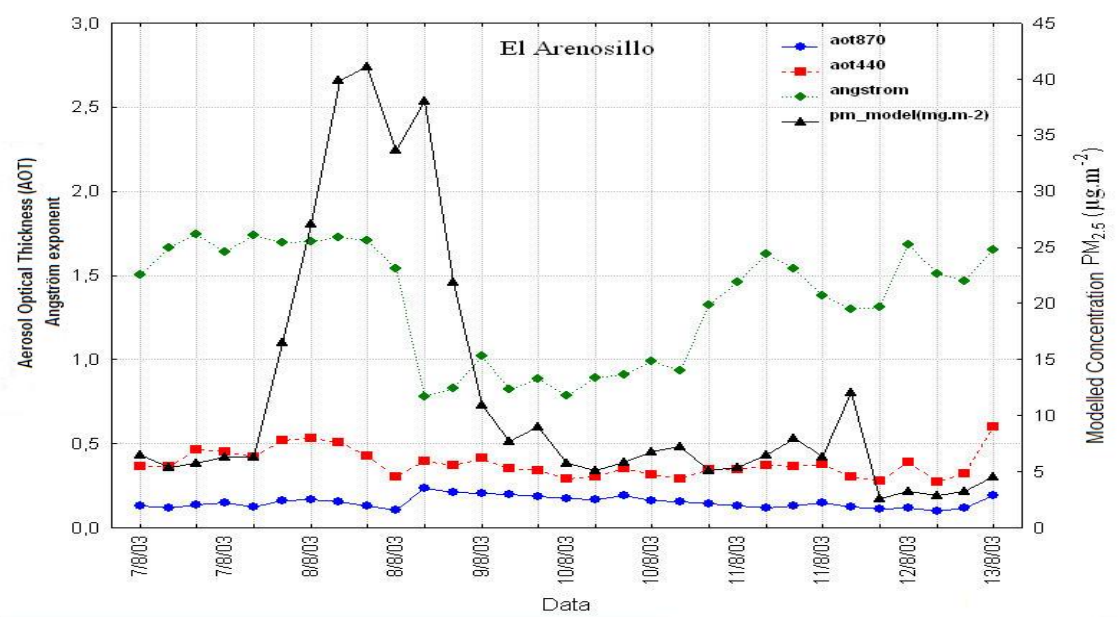

Figure 3: Time series of aerosol optical thickness from AERONET in the $440 \mathrm{~nm}$ and $870 \mathrm{~nm}$ wavelengths, Angström exponent and modelled column concentration of $\mathrm{PM}_{2.5}\left(\mu \mathrm{g} . \mathrm{m}^{-2}\right)$ simulated by CATT-BRAMS in El Arenosillo city $\left(37.105^{\circ} \mathrm{N} ; 6.73347^{\circ} \mathrm{W}\right)$, Spain on the period from 7 to 12 August 2003.

\section{Conclusions}

The general performance of the model presented in this paper, lead to believe that the mesoscale models are a useful tool to simulate aerosol concentration values, reasonably well, in comparison with the aerosol optical thickness at two wavelengths measured at the same sites where modeled values were generated. The sources emission from biomass burning and technological activities for several gases and aerosol may be defined from several published dataset and remote sensing. The biomass combustion emits gases and aerosol particles that interact efficiently with the solar radiation affecting the microphysical processes, dynamics of cloud formation and air quality. The contamination caused by fires can reach distant areas from the burned region and -o increase the pollution from the urban and industrial sources. Therefore, the understanding and fires impact evaluation through numeric modelling is possible and may identify the interrelations between biosphere and atmosphere characterizing a multidisciplinary study. 


\section{References}

[1] Schmuck, G., San-Miguel-Ayanz, J., Barbosa, P., Camia, A., Kucera, J., Libertà, G., Bucella, P., Schulte E., Flies, R., Colletti, L.. Forest Fires in Europe - 2003 Fire Campaign, Official Publication of the European Communities, SPI.04.124.EN, 2004.

[2] Tripoli, G. J., Cotton, W. R. The Colorado State University threedimensional cloud mesoscale model, 1982: Part I: General theoretical framework and sensitivity experiments, J. de Rech. Atmos., 16, 185-220, 1982.

[3] Tremback, C. J. Numerical simulation of a mesoscale convective complex model development and numerical results, Atmos. Sci. 465, Department of Atmospheric Science, Colorado State University, Fort Collins, CO 80523, 1990.

[4] Grell, G. A., and Devenyi, D. A generalized approach to parameterizing convection combining ensemble and data assimilation techniques, Geophy. Res. Let., 29, no. 14, 2002.

[5] Freitas, S., K. Longo, M. Silva Dias, P. Silva Dias, R. Chatfield, E. Prins, P. Artaxo, G. Grell and F. Recuero. Monitoring the transport of biomass burning emissions in South America, Environmental Fluid Mechanics, 5 (1-2), 135 - 167, doi: 10.1007/s10652-005-0243-7, 2005.

[6] Berge, E. Coupling of wet scavenging of sulphur to clouds in a numerical weather prediction model, Tellus, 45B, 1-22, 1993.

[7] Walko, R. L., Cotton, W. R., Meyers, M. P., Harrington, J. Y. New RAMS cloud microphysics parameterization. Part I: the single-moment scheme, Atmos. Res., 38, 29-62, 1995.

[8] Chen, C. and Cotton, W. R. A one dimensional simulation of the stratocumulus capped mixed layer, Bound-Layer Meteor., 25, 289-321, 1983.

[9] Mellor, G.L., T. Yamada. A hierarchy of turbulence closure models for planetary boundary layers, J. Atmos. Sci., 31, 1791-1806, 1974.

[10] Bossert, J. E. Regional scale flows in complex terrain: An observation and numerical investigation, Paper $N^{o} 472,254$ pp., Department of Atmospheric Science, Colorado State University, Colorado, U.S.A, 1990.

[11] Tremback, C. J., Kessler, R. A surface temperature and moisture parameterization for use in mesoscale numerical models, $7^{\text {th }}$ AMS Conference on Numerical Weather Prediction, Montreal, Canada, Amer. Meteor. Soc., Boston, 355-358, 1985.

[12] Vautard, R., Bessagnet, B., Chin, M., and Menut, L. On the contribution of natural Aeolian sources to small particle concentrations in Europe, testing hypotheses with a modelling approach, Atmos. Environ., 39(18), 3291-3303, 2005. 